\title{
A quantitative and qualitative evaluation of the British Columbia Take Home Naloxone program
}

\author{
Oluwajenyo Banjo MPHc, Despina Tzemis MPH, Diana Al-Qutub MPH, Ashraf Amlani MPH, \\ Sarah Kesselring MPH, Jane A. Buxton MBBS MHSc
}

\section{Abstract}

Background: In August 2012, the British Columbia Take Home Naloxone (BCTHN) program was introduced to help to reduce opioid overdose and its consequences. This study evaluates the BCTHN program, identifying the successes and challenges of implementing a provincial program in Canada.

\begin{abstract}
Methods: In this cross-sectional study, we reviewed the records of the BCTHN administrative program to report on program outcomes (participation and overdose reversals). Focus groups and individual interviews were conducted with 40 clients in Vancouver; 12 individual interviews were completed with service providers, police officers and parents of people who use opioids from both the Vancouver and Interior regions of British Columbia. Qualitative data were analyzed using content analysis and a qualitative descriptive approach.
\end{abstract}

Results: As of March 13, 2014, the BCTHN program had been implemented at 40 sites, trained 1318 participants in overdose prevention, recognition and response, distributed 836 kits to clients and received reports of 85 overdose reversals. Stakeholders were supportive of the program, and clients reported greater confidence in response to overdose. Service providers found the program training materials easy to use and that training increased client engagement. Some of the challenges included difficulty in identifying physician willing to prescribe, recruitment of some at-risk populations (e.g., long-term opioid users and patients with chronic pain), and clients' reluctance to call 911 . We also found that the police had some misconceptions about BCTHN.

Interpretation: The BCTHN program was easy to implement, empowering for clients and was responsible for reversing 85 overdoses in its first 20 months. We suggest communities across Canada should consider implementing take-home naloxone programs and evaluate their findings.

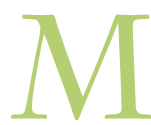
ortality and morbidity related to opioid overdose of both illicit and prescription drugs is a major public health issue worldwide. ${ }^{1-4}$ In 2011 , provisional data from the British Columbia (BC) Coroners Service identified 275 deaths due to drug overdose, and the $\mathrm{BC}$ Ambulance Service administered naloxone, an opioid antagonist that reverses opioid-related respiratory depression, 2367 times. $^{5}$ Take-home naloxone (THN) programs have been implemented to address deaths due to opioid overdose, and hundreds of programs have been in existence in Europe, Australia and the United States since the mid-1990s. ${ }^{6-11}$ THN programs usually combine training for dealing with overdose and naloxone distribution. In Canada, THN programs are relatively new, and we are aware of only 2 published evaluations of community-based THN programs in Edmonton and Toronto. ${ }^{12,13}$

The BCTHN program, developed by the BC Centre for Disease Control (BCCDC) was implemented on August 31, 2012. To participate, sites must identify 3 key components: an educator, a prescriber and a dispenser; and the site must have approval from the regional health authority (Figure 1). Training, which includes overdose prevention, recognition and response using the SAVEME procedure (Figure 2), is provided to people who use opioids, their family and friends, and service providers. However, prescriptions for naloxone kits are given only to people who use opioids; naloxone is a prescription-only medication. ${ }^{5}$ Details about the BCTHN program, including up-to-date-statistics, training materials, videos and posters, are available at www.towardtheheart.com/naloxone.

British Columbia is the only Canadian province with a THN program in continuous operation for over 20 months. We report on the BCTHN program's key measures (participation

Competing interests: None declared.

This article has been peer reviewed.

Correspondence to: Jane Buxton, jane.buxton @ bccdc.ca

CMAJ Open 2014.DOI:10.9778/cmajo.20140008 
and overdose reversals) and describe the program's successes, challenges and recommendations from its first evaluation using quantitative and qualitative methods. We present the perspectives of program stakeholders (i.e., clients and service providers) from sites participating in the initial rollout of the program, of police and of parents of people who use opioids. This report will add to the limited literature currently available in Canada, providing information for those considering participation in and implementation of THN programs.

\section{Methods}

Ethics approval was obtained from the University of British Columbia and the Vancouver Coastal Health and Interior Health ethics boards. Informed consent was obtained verbally from focus group participants and in writing from the participants who were interviewed. A BCTHN community advisory board was developed and includes membership from THN site coordinators, police and people who use drugs. Community Advisory Board members assisted in the development of the question guides and the recruitment of participants for interviews.

\section{Setting}

The BCCDC Harm Reduction Program operates the BCTHN program, which is responsible for developing training materials, enrolling the sites and supplying the overdose prevention kits. BCTHN sites are existing health units or community agencies partnered with health care providers (Figure 1). BCTHN sites are responsible for the training of and dispensing kits to eligible clients and reporting their progress to BCCDC. This study took advantage of the existing program structure: administrative records were reviewed for the quantitative component and participants were recruited from existing BCTHN sites for the qualitative component.

\section{Quantitative component: review of program records}

Forms were developed to track program indicators, including the number of people trained (i.e., service providers and people who use opioids and their friends and family), the number of people receiving a kit for the first time and the number of

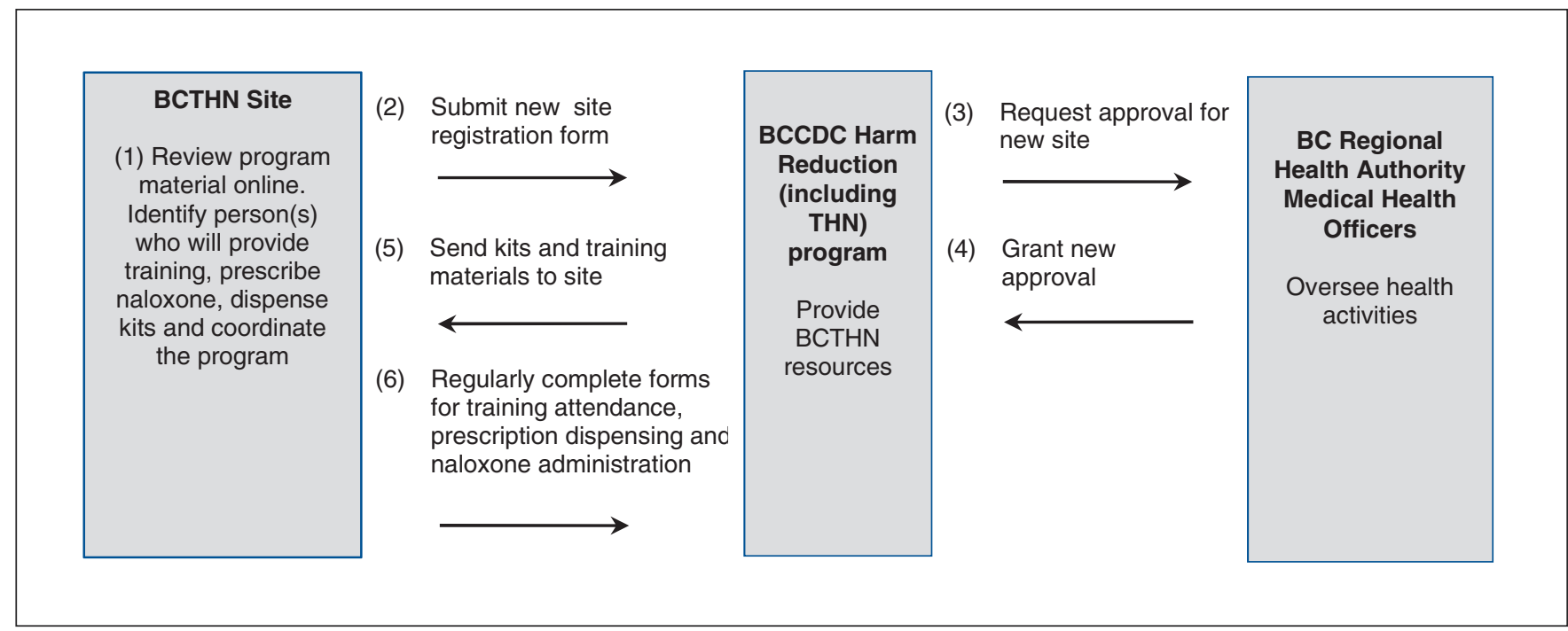

Figure 1: Outline of the responsibilities for each party involved in the British Columbia Take Home Naloxone (BCTHN) program. *e.g., public health unit, community health centre, community agency, hospital emergency department or detox facility. BCCDC = BC Centre for Disease Control.

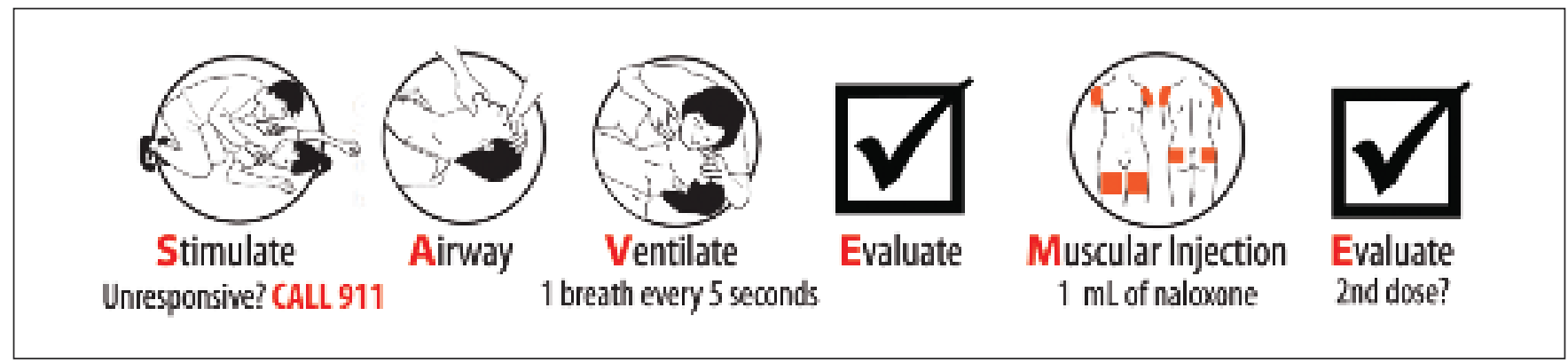

Figure 2: SAVEME poster describing the British Columbia Take Home Naloxone (BCTHN) program response to overdose. SAVEME $=$ stimulate airway ventilate evaluate muscular injection evaluate. 
replacements kits issued, and site coordinators are asked to send these forms periodically to BCCDC, where the information is entered and stored in an administrative database. Data were extracted from this database and analyzed using Microsoft Access and Excel 2007 to generate the frequencies and means for categorical and continuous variables.

\section{Qualitative component: study design, participant recruitment and analysis}

\section{Study design}

After a literature review and input from community advisory board members, we developed semi-structured interview guides for the different stakeholder groups: clients (people who use opioids and have received a kit), service providers (physicians, THN site coordinators and educators), police and parents of people who use opioids. The questions explored perceptions about the program training, resource materials and implementation; they also probed for concerns identified in the literature, such as the ability of people who use opioids to manage overdose situations and to seek medical follow-up after naloxone administration (i.e., to call 911), and the potential for the THN program to increase risk-taking behaviours, stigma and community awareness. ${ }^{14}$ The interview guides were relatively similar across stakeholder groups. Any differences lay in the depth and specificity of some of the questions that were most relevant to that stakeholder. For example, educators may have expanded on the training materials that were developed, whereas police may have focused on misconceptions about the program and community awareness.

\section{Participant recruitment}

Focus group and key informant interview participants were recruited from one urban region (Vancouver Coastal) and one rural region (Interior Health) with active THN sites. Clients aged 19 years and older, who used opioids and had received training at BCTHN sites in Vancouver Coastal, were invited to participate in either a focus group or a face-to-face interview, which took place at the participating site. Vancouver Coastal was chosen as the region for client recruitment because it had 10 of the 20 BCTHN sites running at the time of the study and the most diverse clientele. Clients were recruited by program staff at that BCTHN site and offered a $\$ 10.00$ honorarium for their participation. Service providers at BCTHN sites, including nurses, coordinators and physicians, were emailed invitations to participate in an individual interview. The Community Advisory Board member from the Vancouver Police Department identified front-line officers for individual interviews. Parents of people who use opioids were recruited through parent support groups.

\section{Data collection and analysis}

Data were collected from November 2012 to June 2013. Two investigators (one graduate student and one BCCDC epidemiologist) conducted each focus group, which took approximately 1 hour (one moderated while the other took field notes). The graduate student conducted 20-minute interviews with clients. Interviews with parents, service providers and police were each approximately an hour. Interviews were conducted over the phone or in person at a location that was convenient for the participant.

All focus groups and interviews were audio-recorded and transcribed verbatim; the transcripts were cleaned of identifying data and organized using QSR NVivo (version 8) software. Three co-authors (D.A., O.B. and J.B.) independently analyzed the data using content analysis and a qualitative descriptive approach, which is a low-inference analytic method. ${ }^{15} \mathrm{~A}$ qualitative description approach obtains "straight and largely unadorned" answers relevant to and appreciated by practitioners and policy-makers. ${ }^{16}$

Initial coding was informed and led by the interview guides but was constantly refined as simultaneous collection and analysis provided new insights that prompted changes in the interview guides and analysis. Codes were grouped into similar descriptive categories, which captured variability within and between different stakeholders. The final themes were agreed upon by the analysis team through consensus. Data collection from clients and service providers ended when saturation was achieved. The quantitative and qualitative results were shared with the community advisory board to validate the findings.

\section{Results}

As of March 13, 2014, the program was implemented in 40 sites in BC, including one hospital emergency department. Table 1 provides a summary of the characteristics of the participants who were trained and the number of THN kits

\begin{tabular}{|lrr|}
\hline $\begin{array}{l}\text { Table 1: Characteristics of participants and THN kits } \\
\text { dispensed as part of the BCTHN program }\end{array}$ & $n(\%)$ \\
\hline Characteristic & 1318 & $(100.0)$ \\
\hline Participants trained & & \\
\hline Description of trainee & 692 & $(52.5)$ \\
\hline People who use opioids & 497 & $(37.7)$ \\
\hline Staff and volunteers & 129 & $(9.8)$ \\
\hline Friends and family & 836 & $(100.0)$ \\
\hline Kits dispensed & 692 & $(82.8)$ \\
\hline Received for the first time & 126 & $(15.1)$ \\
\hline Replacement kit & 18 & $(2.1)$ \\
\hline Unspecified & & \\
\hline Reason for replacement of kit & 59 & $(46.8)$ \\
\hline Used & 17 & $(13.5)$ \\
\hline Lost & 15 & $(11.9)$ \\
\hline Stolen & 8 & $(6.3)$ \\
\hline Confiscated & 2 & $(1.6)$ \\
\hline Expired & 25 & $(19.8)$ \\
\hline Unspecified & & \\
\hline Note: BCTHN = British Columbia Take Home Naloxone. & & \\
\hline & & \\
\hline
\end{tabular}




\section{OPEN}

Research

dispensed and replaced. A total of 85 overdose reversals were reported, although we only received program records for 66. Information from the program records of 64 overdose reversals appears in Table 2 . Two events were excluded from the analysis because paramedics arrived before naloxone was administered.

Client feedback was gathered from 4 focus groups (4-7 individuals per group) and 20 face-to-face interviews. Feedback from physicians, coordinators, educators, police and parents was gathered from 12 individual interviews either in person or by telephone. Demographic information for 47 of the 52 participants (data missing for 5 clients) in the qualitative interviews is shown in Table 3. Demographic data for the 35 clients are shown in Table 4. Participants in the focus groups were recruited from the Vancouver area and varied widely in age (24-62 yr), level of education (none to postsecondary) and years of substance use ( $<1$ to $>45 \mathrm{yr}$ ); they were predominately male ( $28 \%$ female to $60 \%$ male, $12 \%$ not recorded).

We describe successes, challenges, recommendations, concerns and misconceptions that emerged from the qualitative analysis under the following headings: program resources, training sessions, client recruitment, administration of THN, site implementation challenges, concerns about seeking emergency medical assistance, overall perceptions of the program and client empowerment.

\begin{tabular}{|c|c|c|c|}
\hline Event characteristic & $n(\%)$ & Event characteristic & $n(\%)$ \\
\hline Naloxone administered to & & Symptoms of withdrawal & \\
\hline $\begin{array}{l}\text { A third party (by the person who was } \\
\text { prescribed the kit) }\end{array}$ & $41(64.1)$ & None & $29(45.3)$ \\
\hline Self & $15(23.4)$ & Mild & $18(28.1)$ \\
\hline $\begin{array}{l}\text { To a person who was prescribed the kit (by a } \\
\text { third party) }\end{array}$ & $2(3.1)$ & Severe & $8(12.5)$ \\
\hline Unknown & $6 \quad(9.4)$ & Unknown & $1(1.6)$ \\
\hline Location of overdose & & No reply & $8(12.5)$ \\
\hline Private residence & $43(67.2)$ & Display of aggression & \\
\hline On the street & $9(14.1)$ & Yes & $9(14.1)$ \\
\hline Hotel & $5 \quad(7.8)$ & No & $41(64.1)$ \\
\hline Supportive housing & $3(4.7)$ & No reply & $14(21.9)$ \\
\hline Other & $2(3.1)$ & No. of ampoules administered & \\
\hline Shelter & $0 \quad(0.0)$ & 1 & $31(48.4)$ \\
\hline No reply & $2(3.1)$ & 1.5 & $1(1.6)$ \\
\hline $\begin{array}{l}\text { Drugs involved (individuals could give more } \\
\text { than } 1 \text { answer) }\end{array}$ & & 2 & $23(35.9)$ \\
\hline Heroin & $60(93.8)$ & 3 & $1(1.6)$ \\
\hline Fentanyl & $12(18.8)$ & No reply & $8(12.5)$ \\
\hline Methamphetamine & $8(12.5)$ & 911 called & \\
\hline Cocaine/crack & $8(12.5)$ & Yes & $25(39.1)$ \\
\hline Methadone & $7(10.9)$ & No & $38(59.4)$ \\
\hline Morphine & $4 \quad(6.3)$ & No reply & 1 (1.6) \\
\hline Benzodiazepines & $4 \quad(6.3)$ & If 911 not called $(n=38)$, why? & \\
\hline Codeine & $2(3.1)$ & Police involvement & $17(44.7)$ \\
\hline Oxycodone & $2(3.1)$ & Would recover on own & $15(39.5)$ \\
\hline Alcohol & $2(3.1)$ & No reply & $6(15.8)$ \\
\hline GHB & 1 (1.6) & $\begin{array}{l}\text { If } 911 \text { called }(n=25) \text {, did police } \\
\text { attend? }\end{array}$ & \\
\hline Other & $6 \quad(9.4)$ & Yes & $13(52.0)$ \\
\hline \multirow[t]{2}{*}{ No reply } & 1 (1.6) & No & $12(48.0)$ \\
\hline & & No reply & $0 \quad(0.0)$ \\
\hline
\end{tabular}




\section{Program resources}

Service providers found that the program website and training materials were comprehensive and easy to use. They reported being able to adapt the training guide to suit client needs (Box 1).

Clients and service providers reported that the posters and video ensured that clients, especially those with low literacy levels, understood the information about overdose prevention, recognition and response.

\section{Training sessions}

Clients and service providers considered the program to be beneficial. Training delivery varied within and between sites: training could be provided to individuals or in groups and could be brief or comprehensive. Most service providers considered individual training as an engagement tool for building relationships and providing other health-related support and information (Box 2).

Service providers reported that clients were often confused about the signs of opioid and stimulant overdoses, which reinforced the need to educate clients about overdose recognition and response. Challenges reported by clients during the training included fear of needles and lack of familiarity with the retractable syringes.

\section{Client recruitment}

Clients reported telling their friends about the program. Service providers reported the most common method of recruitment was word of mouth; some clients found posters in hightraffic areas and tip cards helped recruitment. Patients with chronic pain and people who have used opioids for a long time were resistant to recruitment (Box 3).

Suggestions for promoting community awareness and increasing the reach of the BCTHN program included involving parole officers and methadone prescribers, and increasing outreach through harm reduction facilities, those working with addicts and support groups. One parent sug- gested receiving program information from other parents would encourage parents of people who use opioids to attend training.

\section{Administration of THN}

Clients who have administered naloxone felt it was easy to use and were glad that they had naloxone available (Box 4).

Clients who had not used the kit were confident that they could administer naloxone if necessary. Most clients stated they would be unable to self-administer naloxone in an emergency and had told their friends and family where the kit was kept. Clients reported that the instructional steps in the kit helped to reduce anxiety and reminded them of what to do in overdose situations.

\section{Site implementation challenges}

A few service providers reported some time limitations and having to adjust other programs to accommodate the BCTHN program (Box 5).

Fiscal constraints were also mentioned as challenges to the effective implementation of the BCTHN program. One physician noted that private clinics would need additional financial resources to set up the program and conduct training.

Some clinics and agencies interested in implementing the THN program reported difficulties in identifying physicians willing to be prescribers. There was also concern about program sustainability, in particular, if a prescribing physician withdrew their service.

\section{Concern about seeking emergency medical assistance}

Although clients said they were confident about calling 911 when responding to an overdose, less than half of those who used the kits reported calling (Table 2). The main reasons for not calling 911 were the belief that the person who overdosed would fully recover after naloxone administration and fear of police involvement (Box 6).

\begin{tabular}{|c|c|c|c|c|c|c|}
\hline \multirow[b]{2}{*}{ Participant } & \multirow[b]{2}{*}{$n$} & \multicolumn{3}{|c|}{ Sex } & \multicolumn{2}{|c|}{ Health region } \\
\hline & & Female & Male & Unknown & $\begin{array}{l}\text { Vancouver } \\
\text { Coastal }\end{array}$ & Interior \\
\hline Client $^{*}$ & 40 & 11 & 24 & 5 & 40 & 0 \\
\hline \multicolumn{7}{|l|}{ Service provider } \\
\hline Physician & 2 & 1 & 1 & & 1 & 1 \\
\hline Coordinator & 2 & 1 & 1 & & 1 & 1 \\
\hline Educator (registered nurse) & 4 & 4 & & & 3 & 1 \\
\hline Police & 2 & 1 & 1 & & 2 & 0 \\
\hline Parent & 2 & 2 & 0 & & 2 & 0 \\
\hline Total & 52 & 20 & 27 & 5 & 49 & 3 \\
\hline
\end{tabular}




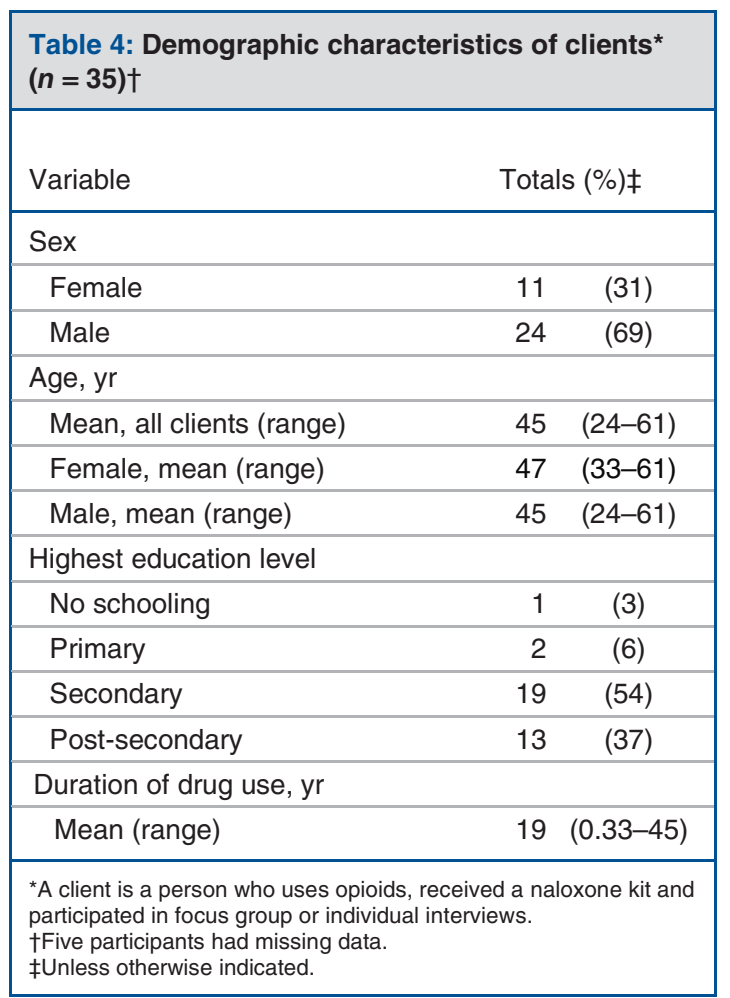

\section{Box 1: Respondent views on program resources}

"www.towardtheheart.com is an incredible website. And it's quite easy to implement the program." - Coordinator [Educator] 1, Rural

"I typically go based on their [the client] knowledge and so sometimes, I don't follow exactly what's in there and we'll have a discussion." - Nurse [Educator] 2, Rural

"Well, the ones who don't read, all they all got to do is watch a video." - Client interview 11, Urban

"There is a lot of stuff in the original guide that I definitely didn't need. ... a lot of it I found really redundant." - Counselor [Educator] 3, Rural

\section{Box 2: Respondent views on the training sessions}

"Groups work fine really. It can go either way but individual I suppose is better. People feel more willing to ask questions." Counselor [Educator] 3, Rural

"There's a lot of things that come out in the training.... One fellow revealed that he hadn't had a physical exam for 6 years so there are other things, other opportunities to talk about health issues." - Coordinator [Educator] 1, Rural

"We are all familiar with Narcan [naloxone], but it was educational. ... Now we've learned how to use it properly. Cause there's a lot of misconceptions, you know or some people may think have to vein line it instead of muscling it." Client 1 (Focus group 3), Urban

"The way [educator] and the [prescriber] did it, you know, it was very detailed, like she actually did the actual snap [of ampoule]." - Client interview 5, Urban
The police were also concerned that clients may become overconfident and fail to get medical attention following an overdose.

When the findings were shared with the community advisory board, members confirmed that the police had confiscated some kits. To address this issue, the BCCDC produced a one-page, illustrated information sheet to inform police about the program. ${ }^{17}$ In November 2013, at a subsequent community advisory board meeting, members did not have any recent reports of confiscations of kits by the police.

\section{Overall perceptions of the program}

Clients, service providers and parents were pleased that the BCTHN program was implemented (Box 7). One of the parents also believed that making naloxone readily available would not increase risk-taking behaviour.

Police were less accepting of the program, stating that the program may be beneficial but not in the environment they work in. The police officers were concerned that naloxone may have a market value and thus promote illegal activities. However, clients reported that naloxone has no market value because it takes away their "high". Clients reported that some naloxone kits were lost during transient housing and others were confiscated by the police (Table 1).

\section{Client empowerment}

Clients reported a strong sense of pride for taking part in the BCTHN program and for having learned the skills to help save someone's life. The majority of clients discussed feelings of empowerment and confidence in responding to an overdose event (Box 8).

\section{Interpretation}

Stakeholders were generally supportive of the BCTHN program. People who use drugs were successfully trained in the BCTHN program, which is consistent with most other evaluations of THN programs in the literature..$^{14,16,18,19}$ Clients reported feeling empowered and were more confident in responding to overdose events, which has been reported in other studies. ${ }^{10,16,19-23}$ Although not measured quantitatively, participants perceived that providing naloxone did not increase drug use or risk-taking behaviour, as has been observed by others. ${ }^{21,22}$ Symptoms of withdrawal or aggression after the administration of naloxone were uncommon, even though more than $40 \%$ of the clients received 2 or more ampoules of naloxone. This helps to alleviate concerns that naloxone administration in community settings will trigger withdrawal and aggression.

Service providers reported that training increased client engagement and use of health care services. This was noted in other studies: a study in Chicago reported that participants in the THN program increased their use of health care services leading to improved personal care and safer practices. ${ }^{10}$ BCTHN service providers found the program easy to implement, but they experienced time and fiscal constraints because programs needed to be balanced with other competing interests 
for staff time and human resources. There are a limited number of physicians in the smaller communities of BC who work with people who use psychoactive substances and within a harmreduction model. Without a local champion to support administrative and training activities or any financial incentives, physicians may find the program time-consuming and may be reluctant to participate. Despite these constraints, the program was identified as a priority that should expand throughout $\mathrm{BC}$ and to various high-risk groups. ${ }^{23}$

Other challenges described by service providers included recruiting people with long-term opioid use to participate in the THN program, because long-term users may underestimate their personal risk and believe they have adopted sufficient harm-reduction strategies to prevent overdose. Because illicit drugs are unregulated, unknown potency and constituents of the drugs increase the risk of overdose. For example, an increase in overdose deaths in $\mathrm{BC}$ was associated with more potent heroin in 2011, and powdered fentanyl was reportedly being sold as heroin in May of 2013..$^{24,25}$

Furthermore, service providers noted that patients prescribed opioids for chronic pain were reluctant to receive naloxone as they did not perceive themselves at risk of overdose (because the opioid was prescribed by a physician) and were concerned with being labelled a "drug user". However, those prescribed opioids may be at increased risk of overdose due to respiratory, renal or liver disease, and may be prescribed other depressant drugs. ${ }^{26-29}$ Education about overdose risks may reduce the stigma associated with drug use and encourage patients with chronic pain to accept the naloxone kits.

Police officers had reservations and misconceptions about the BCTHN program, and several clients had their kits confiscated by the police. We found, similar to other regions, that clients were concerned about police involvement after they called 911. ${ }^{1621}$ Therefore, it is important that local police agencies are engaged to address concerns and encourage people to call emergency health care services in overdose events

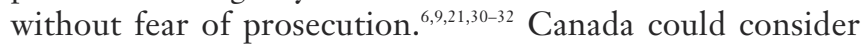
implementing a Good Samaritan law similar to laws in 10 states in the US, which would protect the bystander and the overdose victim from prosecution for drug possession. ${ }^{30}$ The BCTHN training continues to reinforce the importance of calling 911 when an overdose event occurs, because naloxone has a shorter half-life than many opioids and the overdose may recur.

\section{Limitations}

The validity and representativeness of the quantitative data captured in this study are uncertain. There is no systematic follow-up after the clients have been dispensed naloxone, and they may be unable to complete the administration form without a reminder and assistance from a service provider. This likely led to a underreporting of overdose reversals from people participating in the BCTHN program.

We have presented a range of opinions from participants; however, our subjective experiences, as the program's implementers and research team, may play a role in the quotes chosen and ideas presented. Findings from this first evaluation of the BCTHN program may differ from future evaluations when more qualitative data are collected from sites outside the Vancouver region. Because most BCTHN sites were first implemented in the Vancouver region during initial rollout, most

\section{Box 3: Respondent views on client recruitment}

"The challenging ones for me hasn't been stigma but it's been ... veteran users that are sure that they are not going to overdose." - Nurse [Educator] 2, Rural

"I think being well informed and hearing from a parent who took the training would be really helpful." - Parent 2, Urban

"Well, l'd overdosed a few times in there and they know that I use on the street, too. So they right away ... as soon as they started doing this said [client's name], here. We got to teach you this." - Client interview 7 , Urban

"We could spread the word about the program a little bit better, through the justice system piece." - Nurse [Educator] 2, Rural

"I know of one nurse in particular who was against the program and I'm pretty sure had dissuaded participation." - Counselor [Educator] 3, Rural

"New clients who come in for methadone will be offered the take home naloxone program and given a kit." - Nurse [Educator] 5, Urban

\section{Box 4: Respondent views on administration of THN}

"The guy was almost gone.... The ambulance guy said that if we didn't do what we've done [administer naloxone], he wouldn't have made it." - Client 2 (Focus group 2), Urban

"You're worried about dealing with the overdose, right, so ... it was useful to get the instructions on the kits themselves." Client 1 (Focus group 1), Urban

"It was my wife, I didn't use gloves. I wanted to bring her back so ... that was my main concern so ... you know, but she didn't respond after the first one. I waited about a minute and then I gave her the second shot, and then she came to." - Client interview 11, Urban

"... if I had the training and understood when to do it I would have no hesitation at all." - Parent 1 , Urban

\section{Box 5: Respondent views on site implementation challenges}

"I think it's more to do with [BCTHN] being an emerging practice. ... Whenever we're adding aspecial program, that means that we have to balance out some time with all the existing programs that we're doing." - Prescribing physician 1, Urban

"If we lose one of those guys, then we're starting from square one again ..." - Not attributed

"My biggest challenge has been that I'm not technically a clinic so I can't house the kits in my office and that's a big barrier for me.... l'd love to see scheduling of the drug moved to you know." - Nurse [Educator] 2, Rural

"We're a private clinic and I think for us, the big one was you know we needed extra resources like financial resources to pay somebody set up the program and then, do the training." Prescribing physician 2, Rural 


\section{Box 6: Respondent views on the concern about seeking} emergency medical assistance

"She [person who administered naloxone] wanted to call 911, she said and then, everybody who was there was afraid of a drug bust so they didn't." - Coordinator [Educator] 1, Rural

"Follow-up is the biggest [concern] ... I wouldn't count on them [people who use drugs] to call 911." - Police 1, Urban

"I would feel comfortable calling it in, but, like, you know, some people may have, like, you know trouble with the police or, like, they might have warrants. You know what I mean?"

- Client interview 12, Urban

"It's split down the middle. I get half of the people saying 'yeah of course, I will call 911' and they're ok, they hear that and then the other half it's like you know, l'm explaining the need for calling $911 . .$. I would think its fear of police involvement." - Nurse [Educator] 2, Rural

\section{Box 7: Respondent views on overall perceptions of the program}

"I think it's a really great idea, yeah. Because I could have used it a couple times, you know ... It just feels like forever when they are coming, when you do phone $911 . . . "-$ Client interview 12, Urban

"I don't see [naloxone] as at all being enabling; I see it as a factor that prevents death or serious brain damage and other harms." - Parent 2, Urban

"I see the benefits. I definitely see that but for functional addicts not the ones we see." - Police 1, Urban

"... a lot of addicts get picked up by the police and these Narcan [naloxone] kits are just being taken from them." Client interview 1, Urban

"I'm just thrilled that the government is actually taking the time now to do this. Like, this is money very well spent, okay. It's a lot cheaper for one of those kits than it is for a funeral." Client interview 11, Urban

"I just think it would have been nice to have [naloxone].... It would have been good to have that to save a life because eventually he did die from an overdose." - Parent 1 , Urban

"I don't know why BC took so long to get this program here but now that it's here, I'm really hoping that it's going to stay for a while because it really. ... It can really save people's lives." Prescribing physician 2, Rural

\section{Box 8: Respondent views on client empowerment}

"How do I feel about carrying [the kit] in public? I feel proud.... And l'll sometimes say a joke, 'You ain't dying with me around:' — Client interview 11, Urban

"It just felt good to be able to have something that might be able to save somebody." - Client 2 (Focus group 1), Urban "I've heard a lot from not just my peers but from clients in here because I know them so well. Some of them say, 'You know, it's really awesome that I know this.' ... They're all proud and happy." - Client interview 5, Urban

"I think this is bringing ... by coming here I've gotten my selfesteem back, some dignity back, you know. I don't feel like a scummy junky. I feel like a guy with an illness. And l'm going here and I'm getting my help." - Client interview 7, Urban qualitative focus groups and interviews were conducted in this region; however, the study team did reach out to the workforce of health care services in the Interior region, which had the second largest number of participating sites. Opinions expressed by study participants may differ from those of the general community, because they were a convenience sample selected from those currently enrolled in the BCTHN program and may have been most supportive of the BCTHN program.

\section{Conclusion}

The BCTHN program is reducing harms and deaths from overdose, is easy to implement and is supported by stakeholders. However, there are time and fiscal constraints, and the program is reliant on engaging and retaining prescribers. Stakeholder concerns and misconceptions should be addressed, and people who use opioids should be encouraged to contact emergency health care services during overdose events. Our findings highlight the success of the BCTHN program and suggest other communities across Canada should consider implementing THN programs to prevent harms from opioid overdoses. Additional research is needed to determine the success of such programs in rural or remote settings, as well as for patients who are prescribed opioids.

\section{References}

1. Guidelines for the psychosocially assisted pharmacological treatment of opioid dependence. Geneva (Switzerland): World Health Organization; 2009.

2. Caplehorn JR, Dalton MS, Haldar F, et al. Methadone maintenance and addicts' risk of fatal heroin overdose. Subst Use Misuse 1996;31:177-96.

3. Degenhardt L, Bucello C, Mathers B, et al. Mortality among regular or dependent users of heroin and other opioids: a systematic review and meta-analysis of cohort studies. Addiction 2011;106:32-51.

4. Dunn KM, Saunders KW, Rutter CM, et al. Opioid prescriptions for chronic pain and overdose: a cohort study. Ann Intern Med 2010;152:85-92.

5. Harm Reduction Program. Take home naloxone: backgrounder. Vancouver (BC): BC Centre for Disease Control; 2012. Available: http://towardtheheart.com /assets/uploads/files/Backgrounder_2012.08.29.pdf (accessed 2014 Jul. 14).

6. Centers for Disease Control and Prevention (CDC). Community-based opioid overdose prevention programs providing naloxone - United States, 2010. MMWR Morb Mortal Wkly Rep 2012;61:101-5.

7. Coffin PO, Sullivan SD. Cost-effectiveness of distributing naloxone to heroin users for lay overdose reversal in Russian cities. 7 Med Econ 2013;16:1051-60.

8. Coffin PO, Sullivan SD. Cost-effectiveness of distributing naloxone to heroin users for lay overdose reversal. Ann Intern Med 2013;158:1-9.

9. Tobin KE, Sherman SG, Beilenson P, et al. Evaluation of the Staying Alive programme: training injection drug users to properly administer naloxone and save lives. Int 7 Drug Policy 2009;20:131-6.

10. Maxwell S, Bigg D, Stanczykiewicz K, et al. Prescribing naloxone to actively injecting heroin users: a program to reduce heroin overdose deaths. 7 Addict Dis 2006;25:89-96.

11. Baca CT, Grant KJ. Take-home naloxone to reduce heroin death. Addiction 2005;100:1823-31

12. Dong KA, Taylor M, Willa-Roel C, et al. Community-based naloxone: a Canadian pilot program. Can 7 Addiction Med 2012;3:4-9.

13. Leece PN, Hopkins S, Marshall C, et al. Development and implementation of an opioid overdose prevention and response program in Toronto, Ontario. Can f Public Health 2013;104:e200-4.

14. McAuley A, Best D, Taylor A, et al. From evidence to policy: the Scottish national naloxone programme. Drugs Educ Prev Policy 2012;19:309-19.

15. Sandelowski M. Whatever happened to qualitative description? Res Nurs Health 2000;23:334-40.

16. Piper TM, Stancliff S, Rudenstine S, et al. Evaluation of a naloxone distribution and administration program in New York City. Subst Use Misuse 2008;43:858-70.

17. Harm Reduction Program. Overdose prevention kit. Vancouver (BC): BC Centre for Disease Control; 2013. Available: http://towardtheheart.com/assets/naloxone/bcpolice-1-pager-final_90.pdf (accessed 2014 Jul. 14).

18. Dettmer K, Saunders B, Strang J. Take home naloxone and the prevention of deaths from opiate overdose: two pilot schemes. BMF 2001;322:895-6. 
19. Green TC, Heimer R, Grau LE. Distinguishing signs of opioid overdose and indication for naloxone: an evaluation of six overdose training and naloxone distribution programs in the United States. Addiction 2008;103:979-89.

20. Darke S, Hall W. The distribution of naloxone to heroin users. Addiction 1997;92:1195-9.

21. Seal KH, Downing M, Kral AH, et al. Attitudes about prescribing take-home naloxone to injection drug users for the management of heroin overdose: a survey of street-recruited injectors in the San Francisco Bay Area. 7 Urban Health 2003;80:291-301

22. Bennett T, Holloway K. The impact of take-home naloxone distribution and training on opiate overdose knowledge and response: an evaluation of the THN project in Wales. Drugs Educ Prev Policy 2012;19:320-8

23. Eggertson L. Take-home naloxone kits preventing overdose deaths. CMAJ 2014; $186: 17$.

24. BC Ministry of Public Safety and Solicitor General. BC Coroners Service warns of rise in beroin-related deaths [news release]. 2011 May 5. Available: http://www2.news.gov.bc.ca/news_releases_2009-2013/2011PSSG0059000493.pdf (accessed 2014 Jul. 14).

25. Office of the Provincial Health Officer. Spike in fatal fentanyl overdoses sparks warning in BC. CBC News 2013 May 31. Available: www.cbc.ca/m/touch /Canada/british-columbia/story/1.1404744.

26. Albert S, Brason FW, Sanford CK, et al. Project Lazarus: community-based overdose prevention in rural North Carolina. Pain Med 2011;12(Suppl 2): S77-85.

27. Centers for Disease Control and Prevention (CDC). Unintentional poisoning deaths-United States, 1999-2004. MMWR Morb Mortal Wkly Rep 2007;56:93-6.

28. Hall AJ, Logan JE, Toblin RL, et al. Patterns of abuse among unintentional pharmaceutical overdose fatalities. 7AMA 2008;300:2613-20.

29. Office of the Medical Health Officer. Alert for physicians and pharmacists. Prescription opioid overdose deaths of persons with chronic pain in the Interior Health region; 2012. Kelowna (BC): British Columbia Interior Health. Available: www.interiorhealth.ca/AboutUs/Leadership/MHO\%20Updates/MHO\%20 Update\%20October\%209,\%202012.pdf.

30. Bennett AS, Bell A, Tomedi L, et al. Characteristics of an overdose prevention, response, and naloxone distribution program in Pittsburgh and Allegheny County, Pennsylvania. 7 Urban Health 2011;88:1020-30.
31. Enteen L, Bauer J, McLean R, et al. Overdose prevention and naloxone prescription for opioid users in San Francisco. 7 Urban Health 2010;87:931-41.

32. Davis C, Webb D, Burris S. Changing law from barrier to facilitator of opioid overdose prevention. 7 Law Med Ethics 2013;41(Suppl 1):33-6.

Affiliations: British Columbia Centre for Disease Control (Banjo, Tzemis, Al-Qutub, Amlani, Kesselring, Buxton), Vancouver, BC; Faculty of Health Sciences (Banjo), Simon Fraser University, Burnaby, BC; School of Population and Public Health (Al-Qutub, Kesselring, Buxton), University of British Columbia, Vancouver, BC

Contributors: Despina Tzemis, Diana Al-Qutub and Jane Buxton were responsible for the study design. Oluwajenyo Banjo, Despina Tzemis and Ashraf Amlani were responsible for the literature review. Oluwajenyo Banjo, Despina Tzemis, Diana Al-Qutub and Sarah Kesselring conducted the qualitative interviews. Oluwajenyo Banjo, Diana Al-Qutub, Sarah Kesselring and Jane Buxton were responsible for the qualitative analysis. Ashraf Amlani and Jane Buxton were responsible for the quantitative analysis. Jane Buxton was the project lead. All of the authors critically revised the manuscript, approved the final version submitted for publication and agreed to act as guarantors of the work.

Acknowledgements: The authors appreciate the support of the BC Centre for Disease Control (an agency of the Provincial Health Services Authority) and the BC Ministry of Health during the implementation of this program. The authors would like to acknowledge the assistance of Erin Gibson, Dylan Collins, Kristy Williams, program clients and staff, study participants, and the members of the BCTHN Community Advisory Board. No external funding was needed for this study.

Supplemental information: For reviewer comments and the original submission of this manuscript, please see www.cmajopen.ca/content/2/3 /E153/suppl/DC1 